\title{
Educar los cuerpos latinos. Políticas eugenésicas y cultura física en Argentina, Brasil y Colombia (1920-1940) ${ }^{1}$
}

\author{
Educating Latin bodies. Eugenic policies and physical culture in \\ Argentina, Brazil and Colombia (1920-1940)
}

\author{
Eduardo Lautaro Galak \\ Orcid: https://orcid.org/0000-0002-0684-121X \\ CONICET, Instituto de Investigaciones en Humanidades y Ciencias Sociales, \\ Universidad Nacional de La Plata, La Plata, Argentina, eduardogalak@gmail.com
}

Received on 10/05/2020 - Approved on 20/05/2020

\section{Resumen}

La retórica característicamente occidental y moderna que indica que el fortalecimiento del músculo deviene en un perfeccionamiento de la raza anida en sentidos "oficiales" institucionalmente centralizados que se difundieron mediante distintos mecanismos entre las décadas de 1920 y 1930, los cuales hicieron posible la masificación de la cultura física por fuera de los muros escolares. El resultado de estos procesos fue la utilización de los ejercicios físicos para transmitir un ethos determinado y un sentido del (cuidado del) cuerpo simultáneamente como obligación individual y responsabilidad colectiva. Para desarrollar esta problemática se analizaron los discursos pedagógicos sobre mejoramiento de la raza a raíz de fortalecer los cuerpos en revistas educativas y en distintas fuentes históricas argentinas, brasileras y colombianas.

Palabras clave: Eugenesia. Cuerpo. Cultura Física. Educación. Latinoamérica.

\begin{abstract}
Modern occidental rhetoric ensures that muscle strengthening is a synonym of improvement of the race. This was institutionally centralized "official" speech transmitted through different mechanisms between the 1920s and 1930s, making possible the modification of physical culture outside the school walls. The result of these processes was the use of physical exercises to transmit an ethos and a sense of (correctness) body, simultaneously as individual obligation and collective responsibility. To develop this, were analyzed in historic educational Argentinean, Brazilian and Colombian magazines the pedagogical discourses on improvement of the race as a result of strengthening the bodies and the Nation.
\end{abstract}

Keywords: Eugenics. Body. Physical Culture. Education. Latin-america. 


\section{Resumo}

A retórica caracteristicamente moderna e ocidental que indica que o fortalecimento muscular significa um melhoramento da raça é possível de ser analisada nos sentidos "oficiais" centralizados e institucionalizados, espalhados por diferentes mecanismos entre as décadas de 1920 e 1930, possibilitando a massificação de cultura física fora dos muros da escola. O resultado desses processos foi o uso de exercícios físicos para transmitir um certo ethos e um senso de (cuidado do) corpo simultaneamente como obrigação individual e responsabilidade coletiva. Para isso, foram analisados discursos pedagógicos sobre o aperfeiçoamento da raça como resultado do fortalecimento dos corpos em revistas educacionais e diferentes fontes históricas da Argentina, Brasil e Colômbia.

Palavras-chave: Eugenia. Corpo. Cultura física. Educação. Latino América.

\section{Punto cero}

La retórica característicamente occidental y moderna que indica que el fortalecimiento del músculo deviene en un perfeccionamiento de la raza anida en sentidos "oficiales" institucionalmente centralizados que se difundieron mediante distintos mecanismos entre las décadas de 1920 y 1930, los cuales hicieron posible la masificación de la cultura física por fuera de los muros escolares. Ello puede verse con claridad en las novedosas y constantes campañas de salubridad pública y asistencialismo que se sucedieron durante el segundo cuarto del siglo XX en diversos países latinoamericanos, produciendo como consecuencia la proliferación de espacios para el desarrollo de prácticas corporales, el auge de los deportes como medio de representación de discursos patrióticos y la popularización de la gimnasia como dispositivo transmisor de sentidos higiénicos y eugenésicos, entre otros hechos. El resultado de estos procesos fue la utilización de los ejercicios físicos para transmitir un ethos determinado y un sentido del (cuidado del) cuerpo simultáneamente como obligación individual y responsabilidad colectiva. Procesos que, como consecuencia, pusieron definitivamente la educación del cuerpo al servicio de la política.

Para desarrollar esta problemática se analizaron los discursos pedagógicos sobre mejoramiento de la raza a raíz de fortalecer los cuerpos en distintas fuentes históricas argentinas, brasileras y colombianas en revistas educativas. En efecto, se indagaron los impactos que tuvieron las retóricas cientificistas del movimiento político-filosófico eugenésico en el ámbito educativo, a raíz de reflexionar acerca de los sentidos "oficiales" -en tanto gubernamentales o gubernamentalmente legitimados-. Para ello esta investigación se centra en observar los sentidos que se publicaron en dos revistas representativas de los Sistemas Educativos de Argentina y de Brasil, como son la "Revista de Educación" para el primer caso y la "Revista do Ensino" para el segundo -tarea efectuada entre 2013-2014 como parte de los estudios de postdoctorado (UFMG-CAPES)-. A su vez, se incorporan para este 
trabajo una serie de documentos históricos sobre pedagogía de los cuerpos en Colombia, los cuales son confrontados con el estudio anteriormente nombrado con el objeto de hacer de las continuidades y rupturas entre los distintos contextos analizados un modo de pensar cómo y por qué perviven sentidos en la cultura física actual.

Por último, cabe señalar que si bien este trabajo se focaliza en la Educación Física como modo institucionalizado característicamente moderno para transmitir saberes ligados al cuerpo y al movimiento, también se reflexiona sobre discursos asociados al trabajo manual y prácticas cuya razón pasa por la dimensión estética, cuestiones que históricamente esta disciplina ha subordinado. En este sentido, la virilidad y la fortaleza como valores socialmente ponderados es resignificada por otros tipos de destrezas del músculo, aunque con similar sentido de beneficio colectivo.

\section{La Hibris}

Observar los puentes que se tejen entre contextos disímiles pero emparentables como el argentino, el brasilero y el colombiano permite comprender la difusión de ideas, la interpretación de las mismas y la búsqueda por su reproducción, cuestiones que posibilitan entender las particularidades y recurrencias entre los procesos políticos ocurridos en Argentina, en Brasil y en Colombia, por separado y en conjunto. Sentidos que se ven claramente en las fuentes analizadas, por las múltiples referencias cruzadas de hechos, palabras, prácticas y autores, las cuales reflejan un entramado de cosmovisiones generales que permiten reconstruir la argentinidad, la brasilidade y la colombianidad de una época, argumentada en la voluntad política de hacer para perfeccionar la Patria, y amparada en una resignificación "eugenésica" de lo que entendían por raza. ${ }^{2}$

Aún con las vicisitudes macropolíticas y microcontextuales, el período entre 1920 y 1940 resultó internacionalmente importante para configurar una serie de signos que condicionan la educación de los cuerpos hasta la actualidad. Por sólo nombrar un par de ejemplos que son analizados, la común utilización del método gimnástico francés propuesto por Georges Hébert, con similares sentidos en ambos márgenes de la frontera argentino-brasilera, demuestra que, a pesar de querer conformar una identidad en oposición a lo que ocurría fuera del país, existen similitudes argumentales transnacionales. De igual modo, la utilización del eclecticismo como estrategia política refleja que la norma era hacer para mejorar y perfeccionar, sin especificar bien en qué consistía lo normal (cuestión que se ve reconfigurada con el afianzamiento de los discursos de la Década infame en Argentina, con los del Estado Novo en Brasil y con los de la Hegemonía conservadora en Colombia, por sus tendencias totalitaristas, aunque en definitiva se transmitieron sentidos heterogéneos con tono homogeneizador). 
Con este telón de fondo se percibe la importancia de explicitar que, aun cuando estas líneas afirmativas tiendan a mostrar cierta coherencia, lo cierto es que existen sobradas muestras en los documentos de las múltiples tensiones que atravesaron los sentidos "argentinos", "brasileros" y "colombianos" de educación eugenésica de los cuerpos entre las décadas de 1920 y 1930. De igual modo, si bien se refiere a sentidos de construcción de la argentinidad, de la brasilidade y de la colombianidad, en rigor de verdad las políticas educativas centralizadas fueron por momentos más una retórica que efectivamente una realidad (por caso, referir a la centralización de la educación en Brasil antes de 1932 es riesgoso -aunque también pervivan formas descentralizadas posterior a esta fecha-). Sin embargo, por la pretensión de mostrar los sentidos oficiales y legitimados que en cada país se desarrollaron, se prioriza el análisis de los discursos dominantes por sobre las disputas que en cada contexto ocurrieron.

Expositivamente este escrito se divide en tres partes. Un primer apartado contextualizador, en el que se establece una relación entre la educación de los cuerpos con las retóricas eugenésicas que tienen por objeto la salubridad pública y el vigor de la raza nacional, observando cómo se legitima políticamente tal relación. Una segunda parte en la cual se explicitan los sentidos sobre educación eugenésica de los cuerpos en Brasil y en Argentina a partir de estudiar respectivamente los discursos pedagógicos para el mejoramiento de la raza y el fortalecimiento de los cuerpos en la "Revista do Ensino" entre su fundación en 1925 hasta el final del recorte temporal propuesto y la "Revista de Educación" entre 1920 y 1940. En tanto que la tercera ensaya algunas reflexiones preliminares sobre el caso colombiano en igual período, confrontando con los sentidos argentinos y brasileros analizados.

\section{Educación de los cuerpos, salubridad pública, patriotismo y eugenesia}

La influencia de los postulados eugenésicos en los dominios del campo de la educación de los cuerpos argentina, brasilera y colombiana es significativa. ${ }^{3}$ Particularmente el período comprendido entre las décadas de 1920 y 1940 está marcado por una serie de reconfiguraciones acerca de cómo educar los cuerpos, pero fundamentalmente por qué y para qué. Históricamente entendido como secundario o complementario, el cuerpo pasa desde el segundo cuarto del siglo XX a ser eje explícito de políticas y blanco de intervención, siendo su escolarización uno de los vehículos predilectos para tal fin. En esta dirección, los posicionamientos sobre la cultura física resultaron objeto de transmisión de sentidos diversos, principalmente orientados como recursos para masificar y popularizar prácticas y discursos sobre salubridad y patriotismo, en su mayoría producto de políticas gubernamentales con tintes chauvinistas.

En efecto, los discursos enfocados explícitamente a la salubridad exponen la retórica justificadora de las campañas públicas, las cuales se vuelven de significativa importancia para el objeto de estudio de la presente investigación ya que incorporan 
a la cultura física en general y la Educación Física en particular como vehículo de transmisión de hábitos de higiene y sanidad, además de mover definitivamente el eje de lo colectivo a lo individual y de lo público a lo privado, movimientos típicamente modernos (Foucault, 1996; Espósito, 2007). Por caso, la re-utilización del lema mens sana in corpore sano como una de las principales argumentaciones para realizar prácticas corporales es una clara muestra de la utilización política de este razonamiento: si tradicionalmente se subordina la escolarización del cuerpo a la del intelecto, desde la década de 1920 en adelante tanto la mens como el corpore pasan a subsumirse a los discursos de lo sano. De esta manera, educar los cuerpos significó no solamente fortalecer los músculos -es decir, modos de hacer- sino también transmitir conductas -esto es, hábitos morales, de higiene o de carácter, teñidos de científicos, modos de ser-, terreno sobre el cual se apoyan los argumentos que permiten su asociación con el movimiento eugenésico.

Por su parte, las prácticas y discursos patrióticos resultan significativos porque, en una época dónde en Argentina, en Brasil y en Colombia re-emergen el autoritarismo con sus formas verticalistas de gobierno, las intervenciones sobre los cuerpos justifican un sentido que se vuelve carne en el campo de la cultura física: la máxima de que hacer ejercicios físicos es beneficio individual cuanto progreso colectivo. Lo cual debe comprenderse en el contexto del pasaje de la República Velha al Estado Novo en Brasil, de la Hegemonía conservadora a la República Liberal en Colombia y del comienzo de la Década infame en Argentina, procesos que ponen al gobierno discursos filo-totalitarios que promulgan sentidos concretos políticos y éticos mediante retóricas patrióticas chauvinistas y morales conservadoras. Más aún si a ello se le suma la conformación del pensamiento que engarza la práctica deportiva como modo de representatividad de la Patria, como en el caso de las justas internacionales, que no por acaso encuentran en este período un auge que se exponencializa, primero por su legitimación social y luego por su masificación y universalización.

Es sólo mediante este telón de fondo que puede entenderse el vínculo indisociable que se establece entre educación de los cuerpos y discursos eugenésicos: ambas retóricas justificadoras de la cultura física, por salud y por el colectivo, amparadas recurrentemente en un cientificismo monolítico, habilitaron para que la pedagogización de los cuerpos persiga el mejoramiento de la raza. ${ }^{4}$

\section{Eclecticismo, lo tradicional y lo moderno en revista: los casos argentino y brasilero}

En los párrafos siguientes se expone la particular relación de los discursos eugenésicos con la educación de los cuerpos en Argentina y en Brasil. Aun con las particularidades y recurrencias de cada contexto, aun con el recorte "pedagógico" para pensar la argentinidad y la brasilidade, el análisis de la "Revista do Ensino" mineira y de la "Revista de Educación" bonaerense permite observar una serie de estrategias editoriales comunes utilizadas para abordar temáticas sobre los 
movimientos, los cuerpos, la cultura física y sus contenidos, confrontadas con las retóricas que promueven fortalecer los músculos para mejorar la raza. Vale aclarar que si bien es posible trazar puentes entre ambas publicaciones, lo cierto es que cada una de ellas presenta particularidades, no solo contextuales sino también respecto a las políticas pedagógicas.

Ahora bien, puede establecerse como primera consideración cruzada que ninguna de las dos publicaciones tuvo líneas editoriales estrictamente homogéneas en su interior ni explicitaron un modo único y unívoco de desarrollar la educación, sino que, por el contrario, el eclecticismo fue la norma. Sin embargo, aunque no tuvieron una intencionalidad de uniformar, sí presentaron una clara intención editorial de informar y formar profesionales que siguieran estrictamente criterios científicopedagógicos legitimados, métodos teórico-metodológicos didácticos oficializados y sepan las reglamentaciones y legislaciones superiores, respetando las modernas maneras educacionales. En otras palabras, aun cuando no todas las notas iban en la misma dirección, y teniendo en cuenta las múltiples interpretaciones de los docentes que impartían las clases, ambas revistas funcionaron como estrategias unificadoras de sentidos, garantizando la difusión de la voz oficial y promoviendo la reproducción de sentidos oficialmente legitimados. De allí que se afirme como característica primera el eclecticismo, que por un lado autorizaba posicionamientos diversos e incluso contradictorios, pero por otro acallaba sentidos al no darles voz.

De hecho, pareciera ser que aún con divergencias, lo que primaba era una heterogeneidad con tono homogeneizador: a fin de cuentas, todos los discursos publicados debían responder a los sentidos legitimados, lo cual refleja que el interés editorial estaba puesto más en el fondo de lo que se quería transmitir que en la forma. Efecto de ello, la "oficialidad" que representaban ambas revistas -que no en todos los casos era necesariamente estatal, pero sí centralizada- cooptó en muchas ocasiones sentidos, publicando notas que simplificaban discusiones.

Ahora bien, cabe destacar que resulta llamativa la todavía constante indefinición del nombre de la asignatura escolar que tiene por objeto explícito la pedagogía de los cuerpos. Esta discusión acerca del nombre, que parecía saldada desde la primera década del siglo XX en Argentina y en Brasil, continúa apareciendo en reiteradas notas publicadas en la "Revista do Ensino" y en la "Revista de Educación". En efecto, aun cuando estaba aceptada la retórica casi universal de denominar "Educación Física" a la materia encargada de la enseñanza de prácticas corporales, aparecen constantemente una serie de términos que funcionan corrientemente como sinónimos: "Ejercicios Físicos", "Gimnasia", "Gimnástica", "Calistenia", "Cultura Física", entre otros, conforman el conjunto de maneras de llamar este espacio curricular. Sin embargo, aun cuando perviva cierta indefinición respecto al nombre de la disciplina escolar encargada de la educación de los cuerpos, continúa reafirmándose, en cada artículo publicado, su importancia como parte de la grilla curricular. Particularmente se utilizan como retóricas justificadoras y legitimadoras las características de "pedagógica", "científica" y "escolar", argumentándose a su vez en la complementariedad que supone educar "lo físico" respecto a "lo intelectual" y "lo moral", manteniendo claramente la herencia de la 
triada spenceriana, discurso sobre el cual se constituyeron los Sistemas Educativos argentinos y brasileros (Galak, 2013).

Además de esta forma de construir una identidad disciplinar por reafirmación, existió una voluntad identitaria por negación: tal como puede observarse corrientemente en los párrafos editados por las revistas analizadas, la cultura física no es estrictamente militarista, no es solo recreación y divertimento, no es simplemente procurar el fortalecimiento muscular y no es únicamente la espectacularización de los deportes. En todo caso, aún con la heterogeneidad de posicionamientos publicados, puede afirmarse que ambas revistas entienden la Educación Física como el conjunto de manifestaciones culturales legitimadas sobre los movimientos, argumentadas pedagógica y científicamente según criterios políticos.

Empero el eclecticismo característico de la "Revista do Ensino" y de la "Revista de Educación", publicando sentidos concretos pero con argumentaciones incluso contradictorias, con una diversidad de posturas llamativas pero que a fin de cuentas tienen idearios comunes, no hay objeciones a pensar la educación de los cuerpos como vehículo o colaborador del mejoramiento científico de la raza, sino todo lo contrario. En efecto, una de las principales razones para ejercitarse, el sentido higiénico de la Educación Física, se transformó rápidamente en sinónimo de sentido eugenésico. En esta dirección, vale aclarar que en la mayoría de los casos las notas sobre educación de los cuerpos no explicitaban seguir el ideario eugenésico, y ni siquiera nombraban este movimiento político-científico-filosófico. Sin embargo, la retórica de que el fortalecimiento muscular deviene en mejoramiento de la raza, la incorporación de argumentaciones psico-pedagógicas para administrar fichas escolares-biotipológicas clasificadoras y la utilización de discursos eugenistas para argumentar las prácticas disciplinares, demuestran la pregnancia que tuvo el ideario eugenésico en los párrafos dedicados a la cultura física.

Lo cual constituye un punto importante para observar la trascendencia que tuvieron los discursos eugenésicos en el campo pedagógico, al mismo tiempo que demuestran que no fueron un bloque único monolítico, sino que resultaron al mismo tiempo un movimiento político-filosófico y una retórica en boga, utilizada en el ámbito educativo sin compromiso intencional, a veces inocentemente, otras con una clara ideología en su trasfondo, pero amparada en que educar implica progresar, perfeccionar, mejorar.

Esto último, además de habilitar la posibilidad de que las notas sobre educación de los cuerpos publicadas tengan un carácter ecléctico, pone de manifiesto una retórica que se hace presente constantemente en el período estudiado: la idea de que mediante la enseñanza se progresa fue una de las principales consignas políticas pedagógicas desarrolladas en el pasaje de la Republica Velha al Estado Novo en Brasil, y por el ideario de la Década infame en Argentina. Precisamente por este movimiento es que puede entenderse la corriente asociación de educar como modo de hacer progresar, mejorar o perfeccionar, la raza, el colectivo, la Patria. 
En relación con lo anterior, resulta interesante destacar la habitual referencia en las notas sobre cultura física a "lo tradicional" y "lo moderno". Aparece comúnmente en las revistas una intencionalidad pedagógica por valorizar "lo tradicional" de la cultura, pero pretendiendo resignificar lo antiguo para proyectar el futuro: en efecto, no resulta casual que ambos países atraviesen durante las décadas de 1920 y 1930 por instancias discursivas que llaman a "refundar" el país, a crear un homem novo para un Estado Novo. En este sentido, retóricas como "científico" o "progreso" se fundieron en sinónimos de "moderno", constituyéndose acríticamente lo moderno como paradigma político-educativo. En otras palabras, se propone un retorno a "lo tradicional" -sin determinar con detalle cómo se construyópero argumentado en la retórica de "lo moderno" como justificadora de las prácticas educativas. Esta característica de los discursos escolarizadores se articuló significativamente con las retóricas cientificistas de mejoramiento de la raza a través de la educación, que precisan de una argumentación definida del ayer y de una proyección políticamente construida del mañana para operar sobre el hoy.

\section{"Ser fuerte para ser útil"}

La característica que aparece en ambas publicaciones pedagógicas respecto a la educación de los cuerpos de confluir "lo tradicional" con "lo moderno", amparada en retóricas que habilitan la (con)fusión con los discursos eugenésicos -que de igual modo entienden la política como la intervención en el presente a partir de planificar para el futuro según una resignificación del pasado-, demuestra que no es azarosa la común y coincidente utilización de la doctrina de George Hébert para educar los cuerpos a través de la gimnasia (hasta ese entonces, principal contenido de la Educación Física): tanto la "Revista do Ensino" como la "Revista de Educación" publicaron varias notas en las que se abogaba la adopción "oficial" de lo que se conoce como Método Francés de Gimnasia o Methode Naturelle.

Este sistema gimnástico que se popularizó internacionalmente de manera vertiginosa durante las décadas de 1920 y 1930, tenía como principal argumentación para la ejercitación de los cuerpos un "retorno a la naturaleza" (Soares, 2003), ${ }^{5}$ a tono con los idearios iluministas en boga, pero al mismo tiempo con un claro ideal utilitarista futuro. ${ }^{6}$ Amparados en las retóricas de "faire des etres forts" y "être fort pour être utile", los discursos del hébertisme permitieron articular ideas pedagógicas, militaristas y patrióticas con eugenésicas: en efecto, en la base del ethos de la doctrina de Hébert se encuentra la misión de "hacer seres fuertes" y la voluntad de "ser fuerte para ser útil", a partir de subsumir al individuo al colectivo, al educarlo para que se ejercite como resultado de "mandatos superiores".

Puede afirmarse que la pretensión de adoptar el Método Natural creado por un militar francés estuvo fuertemente impulsada por sectores educativos que reivindicaban la transmisión de sentidos moralistas y patrióticos que posibilita la cultura física -reafirmando indirectamente el carácter militarista de la Educación Física-, apoyados en el hecho histórico de que en ambos márgenes de la frontera 
argentino-brasilera se estaban viviendo períodos de gobiernos de facto. Precisamente, uno de los procesos comunes que implica la "militarización de los discursos" es la subordinación de lo individual por el bien común, lo cual se encuentra en las bases del hébertisme y resultó una de las principales argumentaciones para utilizar el Methode Naturelle como "oficial". En este sentido, la pretensión de educar los cuerpos para que sean fuertes y útiles, para el ciudadano, para la Patria y para la "raza argentina" o "brasilera", significó una de las justificaciones más corrientes para legitimar y masificar las prácticas públicas de cultura física, como las Plazas de Ejercicios Físicos, las Colonias de Vacaciones, las justas deportivas centralizadas, entre otras.

En lo que respecta a la educación de los cuerpos, existe una llamativa relación histórica entre discursos eugenésicos y militaristas, la cual, aún con argumentaciones particulares y distintivas, refleja cierta imbricación que las hace parecer indisociable. Puede interpretarse que ello se debe a la corriente asociación de la eugenesia con el nazismo, que permitió legitimar y popularizar la doctrina eugenésica como científica, aunque también puede suponerse que ello es producto de que para mejorar la raza en términos más reales que simbólicos es necesaria cierta verticalidad y homogeneización, dos recursos característicos de las doctrinas militaristas.

En definitiva, la tarea individual de fortalecer los músculos se transformó en responsabilidad moral colectiva, sea para el crecimiento del brazo productivo de la ("mano de obra" de la) Nación, sea como responsabilidad profiláctica, no ya solamente del organismo biológico sino también del organismo social. Precisamente, los discursos eugenésicos se apoyan necesariamente sobre esta condición, al partir de la afirmación de que toda política para el mejoramiento científico de la raza se basa en una intervención del cuerpo colectivo de las poblaciones sobre el organismo biológico individual. A su vez, además de este gesto típicamente moderno del período de subsumir lo individual a lo colectivo, se produjo la articulación con otro proceso análogo que se hizo explícito en ese momento, como es el interés por el gobierno de lo privado por parte de lo público. De esta manera, se incorporó como efecto el régimen del auto-control como modelo de control, pasando a ocupar "lo moral" -política que devino en ética- un lugar preponderante en la educación de "lo físico". En última instancia, por las dudas que el auto-control fallase, el poder jurídico punitivo y la policía como brazo armado legitimado del Estado, en pleno auge durante las décadas de 1920 y 1930, se encargaron de recordar a los infractores sus responsabilidades.

\section{Institucionalizar la palabra}

Cabe destacar como estrategia editorial común en las publicaciones estudiadas el peso otorgado a la institucionalización, lo cual es otro gesto moderno característico de la época (que en parte está articulado con la sumisión de lo individual a lo colectivo y con el gobierno público de lo privado). En este sentido, los 
procesos de institucionalización por los que atravesaron las prácticas pedagógicas resultaron ser al mismo tiempo un punto de partida pero también un horizonte político: su legitimación se basó en la racionalidad y sistematicidad de la organización institucionalizada, que ni siempre en su fondo era producto del Estado pero que se apoyaba en las formas del brazo estatal centralizado. Dicho de otra manera: si los procesos de institucionalización son constitutivos de la modernidad -o de lo que podría denominarse como una experiencia trasnacional y transgeneracional compartida, en absoluto universal pero sí universalizante, que encuentra en los grandes relatos sociales, como la Familia, la Iglesia o el Estado, la manera de expresar sus términos-, las décadas de 1920 y 1930 radicalizan esta condición, reconfigurando la institucionalización como modo político legitimado y dominante.

Por caso, los procesos de escolarización como forma institucionalizada y legítima de transmitir maneras de ver, hacer, decir y sentir son un claro ejemplo de esta característica de la época. De hecho, puede esbozarse que el crecimiento exponencial de la institucionalización como modo cultural socialmente reconocido de organización que se inicia en la segunda década del siglo XX, reemplazó el sueño comeniano de materializar la universalización de la escolaridad para enseñarle todo a todos al mismo tiempo, ampliando los alcances de la escolarización: de allí que pueda observarse una coincidencia editorial entre ambas publicaciones al interpretar que la escolarización traspasa lo estrictamente escolar, extendiendo definitivamente las lógicas escolarizantes más allá de los muros de las escuelas.

Por otro lado, la importancia que se le otorga a la institucionalización explica el porqué del constante uso de la "Revista do Ensino" y de la "Revista de Educación" como tribuna política para desarrollar centralizadamente la formación de profesionales encargados de la educación de los cuerpos. De hecho, si bien ambas publicaciones tenían como mandato fundacional el objetivo de actualizar constantemente a los docentes, utilizando para ello la retórica de modernizar los discursos, durante las década de 1920 y 1930 son recurrentes los artículos que paralelamente abogan por una institucionalización que profesionalice específicamente educadores de los cuerpos.

A su vez, la editorialización de ideas pedagógicas en revistas para su masificación es, en sí misma, una clara manifestación de la importancia que supusieron los modos institucionalizados durante este período: no resulta casual que en la década de 1920 sea particularmente significativa la proliferación de publicaciones como modo legitimado de divulgación de palabras y sentidos "oficiales". De hecho, la "Revista do Ensino" es hija explícita de este proceso, tal como puede leerse en la reforma educativa de Minas Gerais impulsada por Mello Vianna en 1925, analizada por Vago (2004; 2006). En esta dirección, el movimiento eugenésico no podría ser pensado sino es atravesado por las lógicas de la institucionalización: las asociaciones pedagógicas y psicologicistas, las ligas profilácticas, de higiene mental, de higiene social o de educación, contra la tuberculosis, el juego (jogo do bicho) o la prostitución, a favor del asistencialismo y del proteccionismo de la infancia, entre otros modos que se produjeron a ambos 
márgenes de la frontera argentino-brasilera, son reflejos de que los discursos acerca de la eugenesia se reprodujeron a través de diversas formas institucionalizadas.

\section{Transmitir sin decir}

Por último, se establecen cuatro consideraciones finales más que refieren mayoritariamente a lo que las revistas analizadas dijeron sin decir o que directamente acallaron.

Primero, el tratamiento compartido por parte de ambas publicaciones analizadas de lo femenino como secundario o, como mínimo, como subespecie que requiere especificidades. En efecto, siempre que se refiere a condiciones dirigidas particularmente a las mujeres se lo explicita: de allí que aparezcan notas sobre "cultura física femenina", "deportes para las mujeres", entre otras. Esta perspectiva sigue reproduciendo el histórico ideario que el cuerpo de las mujeres es débil, aunque en este período se destaca que, a diferencia de tiempos pasados en los que directamente se prohibía cualquier tipo de ejercitación física para las mujeres, esa "debilidad" pareciera ser interpretada en algunos casos como "enfermedad", y que por ello debe ser intervenida. La recomendación de que las mujeres practiquen gimnasias blandas o deportes sin contacto físico directo es un claro ejemplo de esta característica.

Segundo, tal como se esbozó previamente, se produce la definitiva legitimación social de los deportes como potencial contenido escolar, al mismo tiempo que comienza a perfilarse como principal recurso pedagógico de la Educación Física en detrimento de las gimnasias. Si bien esta condición, y teniendo en cuenta que crecen exponencialmente el número de artículos al respecto, no desparecen definitivamente las voces pedagógicas que continúan en contra de la incorporación de los deportes a las escuelas. De hecho, si se tiene en cuenta la masificación deportiva que ocurre en el segundo cuarto del siglo XX y la amplia difusión que se daba en otros carriles comunicativos, es llamativa la poca cantidad de líneas dedicadas a los deportes, lo cual permite esbozar que las lógicas editoriales de la "Revista do Ensino" y de la "Revista de Educación" fueron reticentes a aceptar (y publicar) abiertamente notas que difundan la idea de que los deportes pueden funcionar como recurso pedagógico.

Tercero, que si bien las décadas de 1920 y 1930 resultaron particularmente significativas para desarrollar discursos patrióticos que atravesaron los educativos, exaltando lo nacional por momentos de un modo filo-chauvinista, se utilizaron para ello retóricas importadas del extranjero, particularmente norteamericanas y europeas. En efecto, se produce la paradoja de reafirmar lo propio y lo interno a partir de resignificar argumentaciones ajenas construidas en el exterior.

Por último, que si bien la idea de "raza" aparece comúnmente en las publicaciones de la "Revista do Ensino" y en la "Revista de Educación", no son tan corrientes las especificaciones de lo que significa esa "raza". De hecho, quizás esta 
cuarta cuestión pueda ser explicada en parte por la tercera, gracias a la importación de retóricas (en boga) raciales principalmente de Europa y de los Estados Unidos. Sin embargo, resulta importante destacar que no aparecen referencias de relieve respecto al mestizaje, a la hibridez o a la extranjerización, cuestiones que en otros ámbitos (como el estrictamente eugenésico) estaban comenzando a discutirse con cierta insistencia. Tanto el acento en la españolidad y el desdén por lo gauchesco o aborigen de la "raza argentina", como el destaque de las raíces imperiales portuguesas y la minimización del negro y el mulato de la "raza brasilera", son claros ejemplos de cuestiones que incipientemente aparecieron en las revistas aun cuando su discusión estaba ya instalada en ambos márgenes de la frontera argentinobrasilera.

\section{La "raza colombiana": particularidades y recurrencias ${ }^{7}$}

El período que abarca la década final de la denominada Hegemonía Conservadora y el inicio de la República Liberal hacia 1930 muestra una progresiva industrialización en Colombia, que si bien supuso una modernización política y cultural, no alcanzó a todos los estamentos de la sociedad por igual. En efecto, caracteriza la colombianidad su rasgo heterogéneo, combinando en constante tensión irresuelta la modernidad y la colonialidad, según la tesis de Santiago CastroGómez y Eduardo Restrepo, cuyos discursos oficiales son portadores de fuertes rasgos conservadores y elitistas que ponderan las costumbres católicas patriarcales europeizadas en detrimento de los rasgos culturales de negros, indios y mestizos, a quienes las clases superiores concebían como "razas incapaces de progreso y movimiento" (2008: 236). ${ }^{8}$

En este registro se inscriben también los discursos para el mejoramiento de la raza, entendido como sinónimo de progreso nacional. Al igual que en Argentina y en Brasil, la producción de discursos eugenésicos en Colombia se forjó de la fusión científico positivista médico-pedagógico-jurídica que impactó rápidamente en las retóricas legitimadoras de políticas estatales. Pretendiendo regular prácticas higiénicas de salubridad pública y reglamentar hábitos culturales como la lucha antialcohólica o la prohibición de la prostitución, ${ }^{9}$ el cuerpo resultó el blanco de tales políticas. Dentro de este marco puede encontrarse tanto la Educación Física que se dictaba en las escuelas como la cultura física por fuera de los muros escolares, que de igual modo reprodujeron el ideario pedagógico integralista spenceriano de fortalecer los músculos siguiendo argumentaciones "superiores" morales e intelectuales. De allí que pueda afirmarse que la pedagogización de los cuerpos en Colombia funcionó como un "verdadero laboratorio de profilaxis social" (Herrera Beltrán, 2012: 207), ayudando a curar males morales como la vagancia y la delincuencia, sanar enfermedades culturales como el analfabetismo, transmitir saberes higiénicos, prevenir la malnutrición y fortalecer los músculos. En definitiva, como afirman Andrés Runge Peña y Diego Muñoz Gaviria, toda educación debía tener como objeto el cuerpo y ser, ante todo, práctica (Muñoz et al, 2012: 89), con la 
finalidad de instruir el carácter y formar cuerpos sanos, ascéticos, vigorosos, bellos, disciplinados y auto-controlados acorde a las formas modernas. En efecto, la escolarización en general y la cultura física en particular supusieron modos de modernizar la sociedad colombiana, estableciendo como estrategia civilizatoria la educación como modo de hacer del cuerpo una fuerza económica (Herrera Beltrán, 2012: 53). De esta manera, el caso colombiano también presenta, de modo similar al argentino y brasilero, una sinonimia entre educación, progreso, moderno, racional y científico.

Ahora bien, pueden encontrarse una serie de particularidades de los sentidos políticos que implicaba pensar en educar los cuerpos para mejorar la raza en la Colombia de las décadas de 1920 y 1930, tanto respecto de años anteriores como de lo ocurrido en ambos márgenes de la frontera argentino-brasilera previamente analizado. Según Noguera los discursos eugenésicos e higiénicos del segundo cuarto del siglo XX consolidaron una "moral biológica", con características opuestas a la tradicional moral católica (2003: 97); incluso cuando, con notorias diferencias con Argentina y Brasil, las escuelas públicas colombianas impartían educación religiosa. Precisamente, la razón filosófica que argumenta la búsqueda de un nuevo tipo de moral explica la principal característica del movimiento eugenésico colombiano: si bien existieron distintos posicionamientos que ponderaban cuestiones étnicas, económicas, biológicas o psicológicas, puede establecerse como discurso dominante la intención política de una "regeneración racial". En otras palabras, las tesis de prominentes médicos como Miguel Jiménez López, Bernal Jiménez, Luís López de Mesa, Calixto Torres Umaña o Jorge Bejarano podían diferir en el grado y las razones por las que la "raza colombiana" atravesaba una degeneración, pero en todos los casos coincidían en la posibilidad de intervenir sobre ésta, y entendían que la educación resultaba un importante dispositivo para ello. Así, el problema de la regeneración racial significaba para la mayoría de los intelectuales no un efecto de variables naturales como cuestiones de orden climático, geográfico o biológico, sino un producto de intervención política: de (la ausencia de) políticas públicas de salubridad, higienismo y educación. Como afirma Castro-Gómez, "No son, pues, las razas sino los cuerpos el problema. Bastaría, entonces, con una intervención científicamente avalada sobre esos cuerpos y sobre su medio ambiente para empezar a generar el tipo de sujeto que la industrialización del país estaba necesitando" (2009: 173).

Esta búsqueda de una regeneración racial supone un posicionamiento epistemológico que implica una doble significación articulada que conjuga la idea de generar algo nuevo y mejorado con el propósito de reestablecer algo perdido que se degeneró. ${ }^{10}$ Puede esgrimirse que ello es similar en un punto a las retóricas legitimadoras utilizadas en los ámbitos de la cultura física argentina y brasilera cuando se apelaba al "Método Francés" de gimnástica como mecanismo para mejorar las razas -que en Colombia tuvo escasa influencia-: como una suerte de retorno a una naturaleza primera perdida, el movimiento eugenésico viene a iluminar lo que el paso del tiempo tiñó de oscuridad, viene a proyectar un futuro a partir de rescatar del pasado lo que el presente olvidó, viene a restablecer la pureza que la vicisitudes culturales hicieron un híbrido. 
En relación con ello, otra característica que particulariza el movimiento eugenésico colombiano es que, a diferencia de Argentina, Brasil y otros países latinoamericanos, casi no apeló a la institucionalización de sus postulados. Según explica Noguera (2003: 98-99), una de las razones de por qué se dio esta particularidad se debe a que este país nunca tuvo una inmigración considerable, ni en términos cuantitativos ni cualitativos. Aunque intelectuales médicos de la época como Miguel Jiménez López hayan procurado la llegada de inmigrantes blancos, europeos, industriales y honestos (Castro-Gómez, 2007: 51), e incluso cuando en 1922 se promulgó la Ley no 114 que regulaba el ingreso al país con argumentaciones racistas físicas y morales, ${ }^{11}$ lo cierto es que ello no significó la regeneración racial esperada por autoridades e intelectuales.

\section{Consideraciones finales}

En principio, puede concluirse que los saberes, prácticas y discursos sobre el mejoramiento racial que se desarrollaron en Argentina, Brasil y Colombia, si bien emparentables, no resultaron comparativamente iguales ni homogéneos en su interior. De hecho, extendiendo la tesis de Castro-Gómez y Restrepo (2008: 11), es pertinente antes que referir a una argentinidad, brasilidade o colombianidad en singular, pensar en las conformaciones de "regímenes" en plural: "regímenes de argentinidad", "regímenes de brasilidade" y "regímenes de colombianidad". Del ejercicio de confrontar tales procesos, pero fundamentalmente a partir de interpelar sus particularidades y recurrencias históricas es que es posible desnaturalizar el devenir histórico y afirmar la operación del cuerpo como objeto de políticas públicas, eugenésicas y educativas.

Si bien procesos particulares según cada contexto nacional, existe un eje común en cuanto a los discursos eugenésicos que dominaron la pedagogía de los cuerpos: la gran mayoría de los sentidos políticos acerca de la eugenesia en Argentina, Brasil y Colombia fueron desarrollados en el marco de lo que puede denominarse una "eugenesia positiva", es decir la pretensión de generar un progreso de la raza principalmente a través de la educación y de la masificación de conductas higiénicas, antes que una búsqueda social de calipedia o de curación y eliminación de los menos aptos como aludiría una versión "negativa". Es importante remarcar esto: aún con la militarización de la disciplina que acontecía a nivel internacional en el transcurso de la década de 1930, y aun cuando muchos observaban con buenos ojos lo que por entonces ocurría en Europa, las culturas físicas sudamericanas priorizaron una eugenesia que procure el progreso social y cultural antes que una esterilización de la estirpe. En términos más concretos y directos (y, por ende, más arbitrarios), la intención era higienizar los cuerpos, purificar la moral, vigorizar el pueblo y sanear la población para normalizarla, antes que extirpar los anormales de la sociedad o castrar lo diferente (sea por cuestiones biológicas, naturales, sociales o culturales, pero siempre en términos políticos). 
Sin dudas, el ideario que indica educar los cuerpos para mejorar la raza marca un clima de época que mantiene sentidos tradicionales del campo de la cultura física, como sus características de argumentarse eclécticamente, de considerarse pragmática y pedagógica, de concebirse integralista y al mismo tiempo fragmentaria, de fundamentarse como eminentemente científica, pero que también los resignifica. Sentidos de la episteme disciplinar que son distintivos en Argentina, en Brasil y en Colombia, pero que, sin pretender universalizar exponencialmente, también se reproducen con matices en la mayoría de los contextos modernos occidentales, cuyas principales características asociadas a "lo moderno" perviven hasta la actualidad.

\section{Referencias bibliográficas}

Castro-Gómez, S. y Restrepo, E. (2008). Genealogías de la colombianidad. Formaciones discursivas y tecnologías de gobierno en los siglos XIX y XX. Bogotá: Pensar.

Castro-Gómez, S. (2007). ¿Disciplinar o poblar? La intelectualidad colombiana frente a la biopolítica (1904-1934). Nómadas (Colombia), 26, 44-55.

Castro-Gómez, S. (2009). Tejidos Oníricos: movilidad, capitalismo y biopolítica en Bogotá (1910-1930). Bogotá: Editorial Pontificia Universidad Javeriana.

Castro-Gómez, S. (2010). La Hybris del Punto Cero. Ciencia, raza e ilustración en la Nueva Granada (1750-1816). Bogotá: Pensar.

Espósito, R. (2007). Bios: biopolítica y filosofía. Buenos Aires: Amorrortu Editores.

Foucault, M. (1996). Genealogía del racismo. La Plata: Altamira.

Galak, E. (2012). Del dicho al hecho (y viceversa). El largo trecho de la construcción del campo de la formación profesional de la Educación Física en Argentina. Tesis Doctorado en Ciencias Sociales, Facultad de Humanidades y Ciencias de la Educación, UNLP, La Plata.

Galak, E. (2013). 'Qualquer semelhança com a realidade (não) é mera coincidência'. La constitución de las bases epistémicas de la Educación Física (argentina) frente a la construcción de la disciplina. In: XVIII CONGRESSO BRASILEIRO DE CIÊNCIAS DO ESPORTE. Brasilia. Anais do XVIII CONBRACE - V CONICE, jun. 2013. Disponible en: http://congressos.cbce.org.br/index.php/conbrace2013/5conice/paper/view/4794. Acceso realizado el: 02 Mai. 2020.

Galak, E. (2014a). Raça. In: F. González y P. Fensterseifer (eds.), Dicionário crítico de Educação Física. 3a Edição Revisada e Ampliada. ljuí: Editora Unijuí, p. 558-562. 
Galak, E. (2014b). Educación del cuerpo y política. Concepciones de raza, higienismo y eugenesia en la Educación Física argentina. Revista Movimento, 20(4), 1543-1562.

Galak, E. (2015). 'A educação física busca o aperfeiçoamento da raça': políticas públicas, saúde, eugenia e educação dos corpos. In: Y. Carvalho, A. Branco Fraga, I. Gomes (Eds.), Práticas corporais no campo da saúde (pp. 47-74). Porto Alegre: Rede Unida Editores.

Goís, J.; Lovisolo, H. (2005). A educação física e concepções higienistas sobre raça: uma reinterpretação histórica da educação física brasileira dos anos de 1930 . Revista Portuguesa de Ciências do Desporto, 5(3), 322-328.

Herrera Beltrán, X.; Buitrago, B. (2012). Escritos sobre el cuerpo en la escuela: sujetos, prácticas corporales y saberes escolares en Colombia. Bogotá: Editorial Kimpres.

Muñoz, A. et al. (2012). Educación, eugenesia y progreso: biopoder y gubernamentalidad en Colombia. Medellín: Ediciones UNAULA.

Noguera, C. (2003). Medicina y política. Discurso médico y prácticas higiénicas durante la primera mitad del siglo XX en Colombia. Medellín: Fondo Editorial Universidad EAFIT.

Obregón, D. (2002). Médicos, prostitución y enfermedades venéreas en Colombia (1886-1951). História, Ciências, Saúde, 9, 161-186.

Soares, C. (2003). Georges Hébert e o Método Natural: nova sensibilidade, nova educação do corpo. Revista Brasilera de Ciencias do Esporte, 25(1), 21-39.

Stepan, N. (1991). The hour of eugenics: race, gender and nation in Latin America. New York: Cornell University Press.

Vago, T. (2004). Da ortopedia à eficiência dos corpos: a gymnastica e as exigências da 'vida moderna' (Minas Gerais, 1906-1930). Movimento, 10(3), 77-97.

Vago, T. (2006). Educação física na Revista do Ensino de Minas Gerais (19251935). Organizar o ensino, formar o professorado. Revista Brasileira de História da Educação, 11, 101-134.

Vallejo, G.; Miranda, M. (2005). Darwinismo social y eugenesia en el mundo latino. Buenos Aires: Siglo XXI.

Vallejo, G.; Miranda, M. (2007). Políticas del cuerpo. Estrategias modernas de normalización del individuo y la sociedad. Buenos Aires: Siglo XXI. 


\section{Notas}

${ }^{1}$ El contenido de este texto fue presentado en la mesa "Cultura Física y Educación Física: actores, instituciones, discursos y políticas" del XII Congreso Iberoamericano de Historia de la Educación Latinoamericana, llevado a cabo entre el 15 y el 18 de Marzo de 2016 en Medellín, Colombia. Una versión menos extensa se publica en el libro "Educación, prácticas y cuerpo", editado por Gaviota Marina Conde Rivera, Diana Alexandra Camargo Rojas y Eduardo Galak.

2 Cuestión trabajada conceptualmente en la entrada "Raça" realizada para el Dicionário crítico de Educação Física (Galak, 2014a) y en el análisis realizado en "Educación del cuerpo y política. Concepciones de raza, higienismo y eugenesia en la Educación Física argentina" (Galak, 2014b). Sobre la conformación de la colombianidad se recomienda la lectura de "Genealogías de la colombianidad. Formaciones discursivas y tecnologías de gobierno en los siglos XIX y XX" (CastroGómez y Restrepo, 2008).

${ }^{3}$ Al respecto pueden verse los estudios de Nancy Stepan (1991), Gustavo Vallejo y Marisa Miranda (2005; 2007), de Santiago Castro-Gómez (2010) y de Edivaldo Goís Junior y Hugo Lovisolo (2005).

${ }^{4}$ Precisamente, esto puede verse esbozado en el texto "'A educação física busca o aperfeiçoamento da raça': políticas públicas, saúde, eugenia e educação dos corpos” (Galak, 2015).

${ }^{5}$ Resulta interesante que este discurso del hébertisme refiere a cierto posicionamiento que interpreta la gimnasia como un modo de "retorno a la naturaleza" mediante la ejercitación, dirigido a una población iluminada que coexistía con otros que aún ni siquiera habían salido de la naturaleza. La propuesta del Méthode Naturelle es un romanticismo que a fin de cuentas refleja un problema de clases, una propuesta de "retorno a determinada naturaleza".

${ }^{6}$ Una cuestión tangencial no menor la constituye el hecho de que si bien históricamente la cultura física está asociada a sentidos de utilidad, durante este período analizado sobresalen las notas pedagógicas en la "Revista do Ensino" y la "Revista de Educación" en las cuales se contrapone la "gimnasia" a los "trabajos manuales" como dos modos disímiles de comprender la utilidad de educar los cuerpos (algunos artículos plantean incluso su antagonismo). En efecto, mientras que a las primeras se les adjudica la potencialidad de mejorar el rendimiento físico y producir el descanso de la mente, los segundos beneficiarían el desarrollo de aptitudes para la vida adulta del trabajador.

${ }^{7}$ En estos párrafos se exponen algunas consideraciones iniciales sobre los discursos eugenésicos en Colombia, las cuales serán profundizadas con el trabajo de campo que se realizará en marzo de 2016, gracias a la estancia posdoctoral en la Universidad Pedagógica Nacional, en Bogotá, financiada por el Ministerio de Educación argentino a través de la "Beca Roberto Carri".

8 Precisamente esta tesis de una colombianidad conformada por elementos eclécticos puede ser rastreada en "La Hybris del Punto Cero. Ciencia, raza e ilustración en la Nueva Granada (1750-1816)" de Santiago Castro-Gómez (2010).

9 Para profundizar sobre esta cuestión se recomienda la lectura de "Médicos, prostitución y enfermedades venéreas en Colombia (1886-1951)" de Diana Obregón (2002).

${ }^{10}$ Resulta importante señalar que la idea de una "regeneración" forma parte del ideario político colombiano, aún antes del siglo XX: los libros de historia denominan el período entre 1886 y 1904 precisamente como "La Regeneración", en función de la reforma constitucional que reestructuró cuestiones tradicionales de la vida política y cultural en Colombia, innovando en la federalización pero continuando con rasgos conservadores.

${ }_{11}$ Puede esgrimirse que la prohibición de entrada al país de individuos que por sus condiciones étnicas, biológicas o sociales sean consideradas como un potencial problema para la "raza colombiana" (Muñoz et al, 2012: 69) estaba argumentada en los postulados sobre la degeneración del italiano Cesare Lombroso -quien también había tenido en las primeras décadas del siglo XX una fuerte influencia en el cientificismo positivista en Argentina-. De hecho, según expone Uribe Vergara, Miguel Jiménez López proponía traer inmigrantes para mejorar la raza, cumpliendo tres condiciones: 1) que no exista una desigualdad en la cantidad de llegados al país, 2) que no difieran demasiado en sus caracteres y 3) que esté sometidos por largo tiempo a semejantes condiciones ambientales (Castro-Gómez y Restrepo, 2008: 212). 